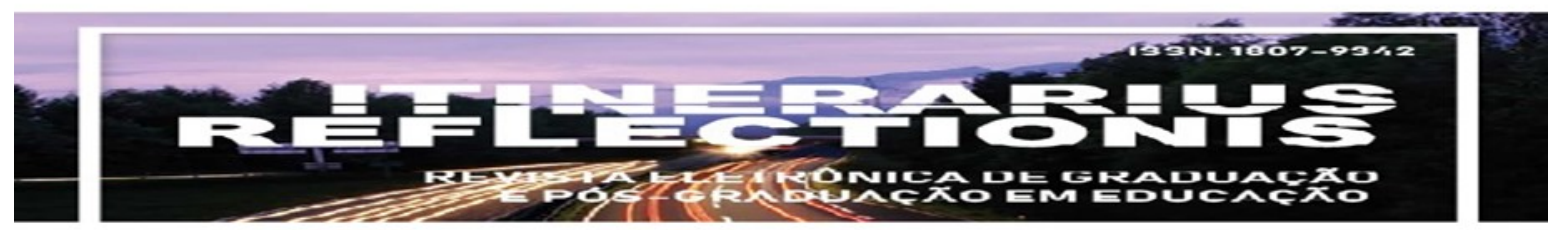

Volume, 15, número 1, ano 2019.

\title{
PIERRE BOURDIEU E O ENSINO NO BRASIL NOS ANOS 1990
}

Cláudia Regina Paese ${ }^{1}$

Resumo. Este artigo tem como objetivo analisar a teoria da reprodução cultural de Pierre Bourdieu aplicada ao ensino brasileiro, a partir dos anos 1990 até a atualidade, com ênfase na reforma do ensino médio e na "escola sem partido". Utilizamos, para tanto, como referência principal, o trabalho publicado em parceria com Jean-Claude Passeron, "A Reprodução: elementos para uma teoria do sistema de ensino", datada de 1978. Esta obra fornecerá subsídios para a discussão e a análise, com o objetivo de compreender as relações histórico-sócio-políticas entre educação e sociedade que produziram as políticas de (em) Educação.

Palavras-Chave: Teorias Crítico-Reprodutivistas; Educação Brasileira; Educação e Sociedade; Política de Educação.

\section{PIERRE BOURDIEU AND TEACHING IN BRAZIL IN THE 1990s}

Abstract. This article aims to analyze the theory of cultural reproduction of Pierre Bourdieu applied to Brazilian education up to the present time. We use the work published in partnership with Jean-Claude Passeron, "Reproduction: elements for a theory of the educational system", dating from 1978, as the main reference. This work will provide support for the discussion and analysis, with the yearning to understand the historicalsocio-political relations between education and society that produced the policies of (in) Education.

Keywords: Critical-Reprodutivist Theories; Brazilian Education; Education and Society; Education Policy.

\section{INTRODUÇÃO}

Nosso trabalho está dividido em três sessões. A primeira abordará a etimologia da palavra reprodução, além da teoria de outros pesquisadores e estudiosos da área, como

\footnotetext{
${ }^{1}$ Doutoranda em Política Social pela Univee Direitos Humanos pela Universidade Católica de Pelotas (UCPEL). Bolsista da Capes/Prosup. Mestre em Política Social pela Universidade Federal de Mato Grosso (UFMT). Integrante do grupo de pesquisa POLITIZA da Unb e do grupo de pesquisa Políticas Sociais, Programas de Transferência de Renda, Gênero e Pobreza, da Universidade Católica de Pelotas.
} 
Marx (1989), Althusser (1985), o próprio Bourdieu e Passeron (1978), Bowles e Gints (1976), Baudelot e Establet (1971). A segunda sessão fará um breve relato da história da educação brasileira a partir dos anos 1990 até a atualidade. O objetivo é identificar os sinais prematuros do envolvimento da educação com a teoria da reprodução cultural, retratada por Bourdieu em suas análises, articulando e contemplando uma análise histórico-social e política da educação brasileira. A terceira traz à tona a discussão sobre a reforma do ensino médio e a "Escola sem Partido", movimento originado em 2003, de inciativa do procurador do estado de São Paulo, Miguel Nagib. Nesta sessão, nossa análise se volta ao propósito de desvelar as diferentes pedagogias que resultam em diferentes experiências de ensino/aprendizagem. Estas podem convergir para uma distribuição desigual do conhecimento às diferentes classes sociais, reforçando nelas a reprodução cultural.

\section{REPRODUÇÃ̃}

A partir do que foi dito acima, achamos importante apresentar, primeiramente, a etimologia da palavra reprodução, para tornar mais claro e objetivo o assunto sobre o qual discorremos.

\subsection{Significado da palavra "Reprodução"}

Quando tratamos da etimologia da palavra reprodução, encontramos nos dicionários a ideia de "ato ou efeito de reproduzir", conforme o Aurélio (1986). Em Marx (1867), esse vocábulo remete à noção de que um sistema é estável e que sua estrutura não é afetada em seu funcionamento. ${ }^{2}$

Tratamos, a seguir, das várias abordagens teóricas sobre a reprodução, além da que nos propomos em Bourdieu (1978). São autores como Marx (1989), Althusser (1985), Bowles e Gints (1976), Baudelot e Establet (1971).

\subsection{Marx e a reprodução}

A educação pela escola tem um papel decisivo na reprodução cultural dos indivíduos. Pela sua capacidade de moldagem das consciências, a educação participa na formação e consolidação da ordem social vigente. Karl Marx (1989) se refere a um modo

\footnotetext{
${ }^{2}$ Disponível em: http://bib.praxis.ufsc.br:8080/xmlui/bitstream/handle/praxis/482/5023019-DICIONARIODE-SOCIOLOGIA.pdf? sequence=1 Acesso em: 23 nov. 2016.
} 
de reprodução como um processo contínuo que percorre ininterruptamente as mesmas fases.

Marx (1989) entende a reprodução como produto de uma dominação de classe. Segundo ele, as ideologias da legitimidade implicam que os dominados se reconheçam no papel de dominados. Essas representações de legitimidade levam ao exercício e à perpetuação do poder através de várias instituições, entre elas, o Estado e a Igreja. As relações diferenciadas do homem com o meio de produção constituem o objeto privilegiado do processo de reprodução. Essas relações de produção condicionam a reprodução de uma determinada hierarquia social.

Em Marx (1989), a reprodução refere-se à repetição das mesmas condições materiais do processo de produção. Todo o processo de produção é, ao mesmo tempo, uma reprodução. Nenhuma sociedade pode produzir, a menos que converta uma parte de seus produtos em meios de produção. São as características do capitalismo que fornecem as características do processo de reprodução capitalista. De um lado, os possuidores de dinheiro ou valor; de outro, os possuidores de força de trabalho. Pelas condições materiais de produção, obtém-se o salário, a casa, o emprego, a educação e a saúde - o mínimo para a sobrevivência do indivíduo. Para o autor, o elemento econômico é o principal condicionante da vida em sociedade.

\subsection{Louis Althusser e a Reprodução}

Althusser foi importante para que a teoria de Marx sobre a reprodução fosse mais aprofundada e divulgada nos meios acadêmicos. Althusser focou suas energias com relação ao tema sobre os países capitalistas que estavam em desenvolvimento. Sua teoria também teve a influência do desencanto que ele percebeu em relação às dificuldades de transformação da sociedade capitalista, mesmo diante das revoltas sociais dos anos 1960 nos países mais desenvolvidos.

Althusser (1985) é considerado o intelectual que foi mais fiel à teoria de reprodução de Marx (1989), na qual as relações dos homens com os meios de produção são hierárquicas e desiguais. Para Silva (1992, p. 32), o processo de reprodução das relações sociais está centrado em elementos materiais e este se localiza no centro deste movimento.

Segundo Althusser (1985), a reprodução se dá no campo "das ideologias" dentro da escola e a serviço da classe dominante. Ainda, para o autor, existem os chamados 
"aparelhos ideológicos". Um exemplo é a disciplina "Moral e Cívica" 3 , cuja obrigatoriedade foi estabelecida pelo Decreto-lei $\mathrm{n}^{\circ} 869$, de 12 de setembro de 1969. A disciplina foi extinta do currículo em 1993, por meio da Lei 8.663, assinada pelo expresidente Itamar Franco. Outro exemplo: através da Resolução $n^{\circ} 8$, de $1^{\circ}$ de dezembro de 1971, anexa ao Parecer $n^{\circ} .853 / 71$, o ensino de História foi suprimido para dar lugar aos "Estudos Sociais"4, dados a cargo de professores "polivalentes" nas $1^{\mathrm{a}}$ a $4^{\mathrm{a}}$ séries. Outro caso: "Organização Social e Política do Brasil" (OSPB) foi uma disciplina do $2^{\circ}$ grau que entrou no currículo escolar a partir da consolidação das diretrizes educacionais de 1961. Foi muito utilizada no período de ditadura militar (1964-1985). Exaltava atividades como "hastear a bandeira e cantar o hino nacional".

Para Althusser (1985), a instituição escolar funciona como um aparelho ideológico que tem por função reproduzir relações de produção - o modo de exploração capitalista. Sujeita o indivíduo a uma ideologia que é a própria relação dominantedominado. A escola assume o papel de dominante, controlando, através de mecanismos que tem à disposição, um processo de seleção que provê a uma determinada classe social a ideologia que convém ao seu papel na sociedade.

Ainda para o autor, a reprodução das relações de produção é assegurada, em grande parte, pela estrutura jurídico-política e ideológica. A reprodução das relações sociais é a reprodução das contradições existentes na relação capital x trabalho.

\subsection{Pierre Bourdieu, Jean-Claude Passeron e a Reprodução}

Para Bourdieu e Passeron (1978), a escola é o veículo institucional para a reprodução dos valores culturais. Os autores entendem esta reprodução da cultura

${ }^{3}$ A educação moral e cívica permaneceu no currículo oficial como disciplina escolar e prática educativa em todos os níveis de ensino por 24 anos, até 1993, quando foi revogada pela Lei $n^{\circ}$ 8. 663. Disponível em: http://www2.faced.ufu.br/colubhe06/anais/arquivos/302JulianaMirandaFilgueiras.pdf Acesso em: 23 out. 2016.

${ }^{4}$ Lei Federal 5692/71, que estabelece Estudos Sociais, Comunicação e Expressão e Ciências como componentes do Núcleo Comum de primeiro e segundo graus. Estudos Sociais foram introduzidos no currículo da escola elementar por volta de 1930, quando Anísio Teixeira ocupava a chefia do Departamento de Educação da Secretaria de Educação e Cultura do Distrito Federal, desenvolvendo um trabalho que refletia sua prolongada estadia nos Estados Unidos. Disponível em: http://www.pead.faced.ufrgs.br/sites/publico/eixo4/estudos_sociais/leme.htm. Acesso em: 23 out. 2016.

${ }^{5}$ Foi uma disciplina do ensino básico no Brasil entre 1962 e 1993. Disponível em: http://anais.anpuh.org/wpcontent/uploads/mp/pdf/ANPUH.S23.1163.pdf. Acesso em: 23 out. 2016. 
dominante como uma "violência simbólica". Percebem que a escola contribui de modo decisivo para a consolidação da ordem social vigente através da ideologia repassada, e na transmissão e inculcação diferenciada de valores, ideias, estilos de vida e de educação.

A escola organiza, seleciona e posiciona os indivíduos em papéis previamente determinados pela sociedade. Para Bourdieu e Passeron (1978), a divisão social está centralmente mediada por um processo de reprodução cultural. Essa reprodução se dá por intermédio de valores culturais que são transmitidos muito fortemente pela educação.

A escola não inculca valores, modos e pensamentos dominantes, mas se limita a usar um código de reprodução cultural em que as crianças e os jovens da classe dominante já foram iniciadas no ambiente da família. Esta é importante, pois permite a continuação no jogo da cultura, de interesses e confirma a exclusão de uma determinada classe.

2.4 Samuel Bowles e Herbert Gints e a Reprodução.

No modelo de Samuel Bowles e de Herbert Gints (1976), a raiz das desigualdades encontra-se na estrutura econômica capitalista e na estrutura reprodutivista educacional — "teoria da correspondência" — que contribuem para alimentar a estrutura capitalista, perpetuando o circuito da reprodução. Segundo os autores, há uma comunicação entre sociedade - modo de produção capitalista — e a escola, enfatizando o processo escolar ligado a características da produção econômica capitalista que transmitem a ideologia dominante.

Bowles (1976) destaca que a escola fornece uma força de trabalho disciplinada e habilitada, ao mesmo tempo em que fornece mecanismos de controle social para a estabilidade do sistema capitalista. Gints (1976), ao destacar o vínculo existente entre escolaridade e salário, enfatiza a relevância da formação de atitudes requeridas pelo mercado de trabalho (GINTS, 1971 apud FRIGOTTO,1989, p. 47).

A escola, através de sua subjetividade, - linguagens, códigos culturais estratifica o conhecimento, reproduzindo diferentes grupos sociais. Para Bowles e Gints (1976), a escola ensina de maneira crucial e mais eficaz através da vivência de suas relações sociais hierarquizadas e não através de seus conteúdos explícitos.

Em Bowles e Gints é central a contradição entre as necessidades de legitimação e as necessidades de acumulação no capitalismo, processo no qual a escola está centrada. A escola como agente de educação é elemento decisivo para a manutenção ou transformação da divisão do trabalho. A 
literatura marxista ignora o papel da instituição educacional (SILVA, 1992, p. 67).

Para os autores, há uma reprodução das relações hierárquicas do trabalho através da produção de subjetividades apropriadas que são encontradas na "[...] réplica das relações de dominação e submissão da esfera econômica" (FRIGOTTO, 1989, p. 48).

2.6 Christian Baudelot e Roger Establet e a Reprodução

Para Baudelot e Establet (1971), o sistema escolar “[...] está dividido em canais separados e incomunicáveis, segregados em termos de classe. Esses canais, através de currículos diferenciados, voltam a reproduzir as mesmas classes sociais existentes" (SILVA, 1992, p. 17). Para os autores, haveria dois currículos: um destinado à classe dominante - e este levaria em conta o status; e outro, para os dominados, também chamados de $2^{\mathrm{a}}$ classe.

Segundo os autores, o aluno oriundo da classe trabalhadora traz consigo sua própria ideologia, que seria advinda das organizações sociais, das relações sociais de que participa, ou seja, de fora do ambiente educacional. Sendo assim, para eles, a escola teria o trabalho maior de inculcar a sua ideologia sobre estes alunos trabalhadores: “[...] conhecimento e vida são arbitrariamente separados, e esta só entra na escola nas suas formas fenomênicas; consolida a divisão entre trabalho manual e intelectual, concepção e execução" (ENGUITA, 1993, p. 252-253).

O legado destes autores estudados encontra-se no fazer uma perspectiva histórica da educação brasileira nas décadas de 1960 e 1970, em que fica evidente o reflexo das teorias oriundas da Europa, que trazia em seu bojo a discussão e a diferenciação entre as classes sociais.

\section{HISTÓRICO DA REPRODUÇÃO CULTURAL SEGUNDO PIERRE BOURDIEU APLICADO À EDUCAÇÃO BRASILEIRA}

Para fazer uma análise histórico-sócio-política da educação que permita perceber a reprodução cultural no sistema de ensino brasileiro, segundo Bourdieu, bem como as políticas educacionais desenvolvidas, dividimos o sistema de ensino por questões metodológicas, a partir dos anos 1990 até os dias atuais. 
Vejamos agora, mais especificamente, algumas características da educação neste período, o que mostra o jogo de interesses de quem tem o poder de determinar os caminhos da educação.

3.1 Dos anos 1990 aos dias atuais: a discussão sobre a reforma do ensino médio e a Escola Sem Partido.

Nos anos de 1990, temos a ascensão do neoliberalismo no Governo Collor de Mello (1990-1992), do PRN: “[...] as políticas educacionais, nesse governo, foram marcadas por forte clientelismo, privatização e enfoques fragmentados" (VELLOSO, 1992 apud YANAGUITA, 2011, p. 3). As intenções do governo para o setor foram apresentadas em alguns documentos: o Programa Nacional de Alfabetização e Cidadania - PNAC (1990); o Programa Setorial de Ação do Governo Collor na área de educação (1991-1995) e Brasil: um Projeto de Reconstrução Nacional (1991) (YANAGUITA, 2011).

De 1994 a 1998, e de 1998 a 2002, Fernando Henrique Cardoso (PSDB) investia na concepção de uma educação que visasse à autonomia e à criatividade do indivíduo. Através destes requisitos, este seria responsável pela sua própria educação e, consequentemente, ascensão social.

Quanto ao ensino médio, nos anos de 1990 não ocorreram muitas alterações. Foi dado avanço à chamada "Reforma do Estado", atendendo a determinações de mecanismos internacionais. A chamada "racionalidade econômica" segue a tríade “eficiência-produtividade-rentabilidade" (FRIGOTTO, 2003).

Quanto aos dados (números) de matrículas no ensino médio, “[...]o índice de crescimento anual do ensino médio, muito pequeno até o governo Itamar, acelera substancialmente durante o governo Fernando Henrique” (DURHAM, 2010, p. 159).

Luís Inácio Lula da Silva (PT) governou o país entre 2003 e 2010. Em 2007, em pleno governo de "Lula", a sociedade comemora mais um PNE, com a ousadia de enfrentar alguns problemas mascarados por outros governos. Ainda enfrentamos problemas do passado, a questão do ensino médio e a baixa nas matriculas é investigada: "O ensino médio, apesar do crescimento excepcional ocorrido durante o governo Fernando Henrique, está ainda muito longe da universalização, e a diminuição do ritmo de crescimento durante o governo Lula é preocupante" (DURHAM, 2010, p. 160). 
Segundo o autor, um sistema de ensino depende da expansão do outro. No governo do ex-presidente Lula, "O aumento das taxas de inclusão no ensino médio promoveu, por sua vez, um aumento de matrículas no nível superior" (DURHAM, 2010, p. 160). Esta realidade deixa claro que seu foco principal são ainda os níveis de qualidade do ensino ministrado em todas as escolas de educação básica do país (SAVIANI, 2010). O governo de Dilma Rousseff teve como foco o ensino técnico, nos termos da Lei 12.513/2012, que trata do PRONATEC. Este foi concebido com o objetivo de aumentar a possibilidade de retorno dos trabalhadores ao mercado de trabalho (WALDOW, 2010, p. 1).

Em meio à polarização política e muitas reformas, como a trabalhista e a previdenciária, entra a discussão do novo ensino médio proposto pelo governo do presidente Michel Temer (2016-2018). Existe uma clara tentativa de deixar o ensino médio mais atrativo, - (para quem?) democrático e universal, além de atender a um processo de aprendizagem contínuo denominado de "ação-reflexão-ação".

Mas o que muda, ou melhor, o que está prestes a mudar no ensino médio brasileiro, a partir de 2018? A resposta parece ser simples: o currículo. Mas, mesmo assim, está imbricada em um "ar" de desconfiança e de desafios. Agora, 60\% da carga horária dos alunos deverá atender ao que for estabelecido pela Base Nacional Comum Curricular (BNCC).

Aqui a proposta é de que existam várias escolas de ensino médio, divididas em pretensões do jovem quanto à sua carreira, podendo escolher que área pretende seguir, se quer escolher entre uma das áreas do conhecimento - Ciências da Natureza, Ciências Humanas, Matemática e Linguagens — , ou se está disposto a trabalhar — ir direto ao mercado. Ainda existirá a formação técnica e profissional à disposição.

Gramsci (1978), ao analisar o americanismo e o fordismo, demonstra sua eficiência no tocante ao processo de valorização do capital por meio dos processos pedagógicos, à medida que, a partir das relações de produção e das novas formas de organização do trabalho, são concebidos e veiculados novos modos de vida, comportamentos, atitudes, valores (KUNZER, 2007, p. 1155).

A carga horária deverá ser de 5 horas diárias — hoje são apenas 4 horas. Outra mudança é que deverá se tornar de tempo integral. Quanto ao currículo, ainda é discutida, na Câmara e no Senado, a obrigatoriedade de algumas disciplinas. Duas alterações são interessantes: a primeira é sobre o ensino de língua estrangeira que, de acordo com a 
alteração proposta pelo governo federal, deve ser ofertada desde a $6^{\circ}$ série; a segunda, é a disciplina de educação física, que passa a ser optativa no último ano do ensino médio.

Em meio a tantas discussões sobre sua efetividade, o que se sabe hoje é que o ensino médio não tem agradado aos jovens brasileiros. Isto se reflete na grande evasão, número maior ainda de reprovações, dificuldades de se conseguir vagas e aí por diante.

Neste vasto rol de realidades, ainda está sendo discutido o projeto Escola Sem Partido. A proposta origina-se de um movimento de 2003, de inciativa do procurador do estado de São Paulo, Miguel Nagib. Converteu-se no projeto de lei 193/2016, de autoria do senador Magno Malta (PR-ES). O objetivo é incluir nas diretrizes e bases da educação nacional (LDBEN), Lei no 9.394, de 20 de dezembro de 1996, o programa “Escola sem Partido". Os autores do PL 193 afirmam ser contrários ao que chamam de "doutrinação ideológica" nas salas de aula, dizendo-se preocupados com o grau de contaminação político-ideológica das escolas. Dizem que sua meta é informar e conscientizar os estudantes sobre os direitos correspondentes àqueles deveres, para que eles próprios sejam capazes de exercer a defesa desses direitos, pois, nas salas, de aula ninguém mais poderá fazer isso em seu nome. ${ }^{6}$

O projeto de lei 193/2016 traz claramente uma visão de mundo de uma sociedade conservadora para os dias atuais — século XXI — de tamanho avanço com relação aos direitos sociais, civis e políticos. Segundo seu projeto, a educação faz parte de uma guerra política. A pergunta que podemos fazer neste momento é: quando a educação não fez parte de uma guerra política ou ideológica? Segundo o PL n 193, de 2016, no Art. $2^{\circ}$, a educação nacional atenderá aos seguintes princípios:

I - neutralidade política, ideológica e religiosa do Estado; II - pluralismo de ideias no ambiente acadêmico; III - liberdade de aprender e de ensinar; IV - liberdade de consciência e de crença; V - reconhecimento da vulnerabilidade do educando como parte mais fraca na relação de aprendizado; VI - educação e informação do estudante quanto aos direitos compreendidos em sua liberdade de consciência e de crença; VII - direito

\footnotetext{
${ }^{6}$ Disponível em: http://www.programaescolasempartido.org/. Acesso em: 24 jan. 2017.
} 
dos pais a que seus filhos recebam a educação religiosa e moral que esteja de acordo com as suas próprias convicções. ${ }^{7}$

Os princípios relacionados pelo PL 193, de 2016, já existem em nossa Constituição, ou até mesmo podemos dizer que já estão garantidos. A discussão aqui abordada tem a visão conservadora de mundo que recai em uma reprodução cultural - papel que a escola realiza pela ação pedagógica, seja ela advinda de um plano político pedagógico, seja ela reproduzida em sala de aula pelo professor. Bourdieu (1978) também faz essa crítica à visão de mundo conservadora, quando olha para a escola francesa dos anos de 1970.

Para o autor, a ação pedagógica desenvolvida na escola, por outro lado, seja pelo modo como se impõe, seja pelo conteúdo que impõe, é definida por Bourdieu e Passeron (1978) como correspondendo aos interesses e objetivos da classe dominante. Para estes autores, toda ação pedagógica tem sempre a função de manter a ordem. Ela alcança este objetivo por um sistema de inculcação direta ou de exclusão indireta, baseado em um processo de seleção, com ou sem exames (PETITAT,1994, p. 20).

Assim, o trabalho pedagógico tende a impor o reconhecimento da legitimidade da cultura dominante nos membros das classes dominadas e fazê-los internalizar a disciplina e a censura como autodisciplina e autocensura. $O$ trabalho pedagógico é o melhor substituto da coerção física. Essa dependência da escola acentua os elementos oriundos da classe média, a inculcação dos conteúdos escolares de forma dócil e acrítica. Por outro lado, a ação pedagógica não é um trabalho sistemático que se estenda por toda a vida. Por esta razão, ela visa produzir um treinamento mais durável, falo de um "habitus" (BOURDIEU; PASSERON apud SILVA, 1992, p. 44).

$\mathrm{O}$ arbitrário cultural, a que se referem os autores acima, implica que uma mesma função pode conter uma multiplicidade de conteúdos culturais, como as infinidades de culturas e poderes. A análise de como o sistema de ensino seleciona os conteúdos a serem ministrados é bastante conhecida. A explicação é baseada na existência de diferenças na cultura, diferenças estas de capital cultural adquirido por estas crianças que têm ou não

\footnotetext{
${ }^{7}$ Disponível em: https://www12.senado.leg.br/ecidadania/visualizacaomateria?id=125666. Acesso em: 24 jan. 2017.
} 
acesso a uma cultura diferenciada, que os qualifique e os distingue das demais crianças. A solução para estas desigualdades, segundo os autores, está no desenvolvimento de uma pedagogia que leva em conta as diferenças de rendimento, em função da classe de origem dos estudantes, adaptada a uma didática específica (PETITAT, 1994, p. 31).

Mais tarde, em seus estudos sobre reprodução, Bourdieu e Passeron (1978) passam a desenvolver a teoria da violência simbólica. Segundo eles, a violência simbólica passa a existir definitivamente quando existe uma imposição de uma crença ou de uma língua com a exclusão de outras possíveis, a fim de massificar, tornar aquela realidade única e verdadeira (PETITAT,1994, p. 32).

Bourdieu (1978) foi o representante máximo desta corrente de pensamento. Ampliou o debate sobre educação, desmascarando a pretendida neutralidade que a escola costumava tomar para si - em outras palavras, aquilo que a escola rotulava como desigualdades individuais ou dons, passou a ser visto como desigualdades sociais que a escola reproduz.

Bourdieu e Passeron (1978) nos dão uma panorâmica do sistema de ensino superior francês, com seu papel conservador, ou seja, como uma máquina reprodutora das relações sociais a serviço de uma classe dominante. Sua contribuição é bastante importante no campo da Sociologia da Educação. Consideram a cultura dominante em nossa sociedade a cultura burguesa, que desenvolve entre os jovens da classe dominada habilidades técnicas, para aumentar sua capacidade produtiva como trabalhadores, e, ao mesmo tempo, inculcar entre eles uma atitude de aceitação da ordem estabelecida.

O sistema de ensino torna-se, então, um ritual simbólico de imposições e limitações, e a dinâmica social trabalha na direção da recuperação. As classes dominadas não têm capacidade de luta, apenas oferecem sua resistência em termos de contestação simbólica, indignação em relação a uma ordem pré-estabelecida. É explícito, portanto, que a escola não oferece o mesmo ensino a todas as crianças. O conteúdo ideológico inculcado no sistema primário é o da profissionalização, ou seja, proclama-se a adaptação de uma classe ao mercado de trabalho que a espera. Mantém-se, assim, um grupo de indivíduos como subproduto ideológico da sociedade capitalista.

\section{CONSIDERAÇÕES FINAIS}


A educação brasileira evidenciou sempre a força da reprodução cultural no sistema educacional, aparecendo como instrumento desejado, consciente ou inconsciente, das classes dominantes, que reproduziam relações sociais e ideológicas em defesa de seus interesses. "Assim sendo, a classe dominante faz da educação - em seu sentido estrito - um espaço fecundo para a disseminação das suas idéias e dos seus interesses."8

A produção cultural percorreu um caminho onde à educação e à escola restou apenas realizarem o papel de mediadores de seus produtos em detrimento de uma determinada classe social. A escola, através de sua comunicação — do seu ato de transmitir ideias, mensagens —, enfatiza características, ao usar um código de transmissão cultural que reproduz a continuação dos jogos de interesses entre as classes e confirma a exclusão dos menos abastados.

A tarefa social da escola é reproduzir e, porque não dizer, manter, as relações distintas — relações definidas pela posse de bens materiais e bens simbólicos — entre as classes sociais. Isso ocorre através da capacidade que a escola possui de reproduzir bens simbólicos - a educação, as ideias, etc. — formando, assim, as diferentes classes sociais e preparando os indivíduos para ocuparem seu lugar nestas classes. Estas características, as quais foram discutidas ao longo deste texto, podem ser percebidas no novo ensino médio e também no projeto Escola Sem Partido, que reforçam a posição social e cultural dos indivíduos em sociedade, conforme a teoria exposta por Bourdieu (1978) e tomada como caso de estudo para a educação brasileira.

\section{REFERÊNCIAS BIBLIOGRÁFICAS}

ALTHUSSER, Louis. Aparelhos ideológicos de Estado: notas sobre os aparelhos ideológicos de Estado. Trad. Walter José Evangelista e Maria Laura Viveiros de Castro. 2. ed. Rio de Janeiro: Edições Graal, 1985.

ALTMANN, Helena. Influências do Banco Mundial no projeto educacional brasileiro. Revista Educação e Pesquisa. v. 28, n. 1, São Paulo, jan./jun., 2002.

AURÉLIO, Buarque de Holanda Ferreira. Dicionário Aurélio. Rio de Janeiro. Nova Fronteira. 1986

BOURDIEU, Pierre.; PASSERON, Jean-Claude. A Reprodução: elementos para uma teoria do sistema de ensino. 1978. Ed. Franscisco Alves, Rio de Janeiro, $3^{\mathrm{a}}$ ed.

\footnotetext{
${ }^{8}$ Disponível em: http://www.sbhe.org.br/novo/congressos/cbhe5/pdf/932.pdf.Acesso em: 6 de jun. de 2017.
} 
BOWLES, Samuel; GINTIS, Herbert. Schooling in capitalist America: educational reform and the contradictions of economic life. New York: Basic Books, 1976.

BRASIL. Ministério da Educação. Lei Federal 5692/71. Disponível em http://www.planalto.gov.br/ccivil_03/leis/15692.htm Acesso em: 23 out. 2017

DICIONÁRIO DE $\quad$ SOCIOLOGIA. Disponível em http://bib.praxis.ufsc.br:8080/xmlui/bitstream/handle/praxis/482/5023019DICIONARIODE-SOCIOLOGIA.pdf? sequence=1 Acesso em: 23 nov. 2016.

DURHAM. Eunice Ribeiro. A política educacional do governo Fernando Henrique Cardoso:Uma visão comparada. Novos Estudos, nº 88, 11 novembros 2010.

ENGUITA, Mariano Fernández. Trabalho, Escola e ideologia: Marx e a crítica da educação. Porto Alegre: Artes Médicas, 1993.

ESTABLET, Roger.; BAUDELOT, Christian. L'école capitaliste en France. Paris: Maspero, 1971.

FRIGOTTO, Gaudêncio. A produtividade da escola improdutiva: um (re) exame das relações entre educação e estrutura econômico-social e capitalista. 3. ed. São Paulo: Cortez, 1989.

KRAWCZYK, Nora. Reflexão sobre alguns desafios do ensino médio no Brasil hoje. Cadernos de Pesquisa. v. 41 n.144 set./dez. 2011

KUENZER, Acacia Zeneida . Da dualidade assumida à dualidade negada: o discurso da flexibilização justifica a inclusão excludente. Educ. Soc., Campinas, vol. 28, n. 100 Especial, p. 1153-1178, out. 2007

MARX, Karl. O Capital: Crítica da Economia Política. Livro 1. Vol I. 13a edição, Rio de Janeiro: Bertrand Brasil, 1989.

PETITAT, A. Produção da escola/ produção da sociedade: análise sócio-histórica de alguns momentos decisivos da evolução escolar no ocidente. Porto alegre: Artes Médicas, 1994.

SANTOS, Boaventura de Sousa. Para além do pensamento Abissal: das linhas globais a uma ecologia de saberes. Novos Estudos no 79 São Paulo: Cebrap, novembro, 2007.

SAVIANI, Dermeval. Documento Sistema Nacional de Educação articulado ao Plano Nacional de Educação. Revista Brasileira de Educação. v. 15 n. 44 maio/ago. 2010.

SILVA, Tomaz Tadeu da. O que produz e o que reproduz em educação: ensaios de sociologia da educação. Porto Alegre: Artes Médicas, 1992.

VASCONCELOS. Ricardo Afonso Ferreira de.; AMORIM, Mário Lopes. A Educação profissional sob a lógica empresarial do neodesenvolvimentismo de Lula e Dilma: o PNE e o Pronatec. IV Colóquio Nacional e I Colóquio Internacional. A Produção do Conhecimento em Educação Profissional: A reforma do Ensino Médio (Lei 13.415/2017)E suas aplicações para a educação profissional. Natal/RN. 24 a 27 de julho de 2017.

VELlOSO, Jacques. Políticas do MEC e recursos para o ensino no governo Collor. Educação \& Sociedade, n. 42, p. 256-267, ago. 1992. In YANAGUITA, Adriana Inácio. As Políticas Educacionais no Brasil nos anos 1990. XXV Congresso Brasileiro. II Congresso Ibero- Americano de Política e administração da Educação Jubileu de Ouro da ANPAE (1961-2011) São Paulo, Brasil. 26 a 29 de abril de 2011. Biblioteca ANPEA. Série de Cadernos no 11 de 2011 
WALDOW. Carmem. As políticas educacionais do governo Dilma: A formação para o trabalho e a questão do pronatec: reflexões iniciais. X ANPED SUL, Florianópolis, outubro de 2014.

YANAGUITA, Adriana Inácio. As Políticas educacionais no Brasil nos anos 1990. XXV Congresso Brasileiro. II Congresso Ibero-Americano de Política e administração da Educação Jubileu de Ouro da ANPAE (1961-2011) São Paulo, Brasil. 26 a 29 de abril de 2011. Biblioteca ANPEA. Série de Cadernos nº 11 de 2011. 